\title{
Several Aspects of GDPR in the World of Research - What Can We Expect? With Czech Perspectives
}

\author{
JIŘí KOLMAN*
}

\begin{abstract}
The Czech Academy of Sciences and Czech universities are in the beginning of the implementation of the General Data Protection Regulation (GDPR). How to deal successfully with the GDPR in a specific environment that is often international, funded by many resources (a mixture of various national and international, public and private funds and companies, with their own financial and administrative rules), having their specific tasks, missions and cultures (academic freedoms, scientific excellence, competitive environment)? This article focuses on the GDPR's impact on the life of the research entities, such are research institutes and universities. The GDPR is an EU regulation that should have equal legal effect over the entire European Union; however, in certain specific parts of the GDPR specific implementing legislative measures are expected of the EU member states. Moreover, due to different history of the legislation regulating personal data protection in each EU member state, the article focuses mainly on the area of the Czech Republic. The scope of this article is limited to specific issues of scientific life (e.g. open access, open data, peer review), other general aspects of the GDPR (e.g. handling the employees' personal data, the personal data of research subjects) are not the objects of this text.

Keywords: Data Protection Law, Regulation (EU) 2016/679, GDPR, Personal Data, Scientific Freedom
\end{abstract}

\section{INTRODUCTION ${ }^{1}$}

\subsection{GDPR and Research Field}

The Regulation 2016/679 of the European Parliament and of the Council of 27 April 2016 on the protection of natural persons with regard to the processing of personal data and on the free movement of such data, and repealing Directive 95/46/EC (General Data Protection Regulation - GDPR) applies from 25 May 2018. This article focuses on the possible impacts of the GDPR on the scientific world, such as e.g. open access, open data issues, impact on the peer review process used mainly in scholarly journals, funding agencies and research assessment.

For the purpose of this paper, only the main specific procedures are here pointed out that are related to the scientific and academic world and that are related to the GDPR agenda.

1. Open access (free publication of the scientific results);

2. Open data (open publication and share of the scientific data);

3. Czech public universities and public research entities are, according to Czech legislation (Act No. 106/1999 Coll. on Free Access to Information), legally bound under a duty to provide information related to their powers;

* Scientific secretary, Global Change Research Institute of the Czech Academy of Sciences. E-mail: Kolman.j@czechglobe.cz.

1 The paper was written under a collaboration project with Safetica Technologies - cybersecurity and data protection company. This work was supported by the Ministry of Education, Youth and Sports of the Czech Republic within the National Sustainability Program I (NPU I). Parts of the earlier versions of this paper were presented at 15th International Conference on Cyberspace (24-25 November 2017, Brno, Czech Republic). 
4. Peer review process;

5. International scientific collaborations (consortium projects and research infrastructures).

\subsection{Scope of the GDPR}

Before answering related questions envisaged in this paper, the scope of the GDPR will be briefly analysed from a legislative point of view. As it is a regulation, it should be conformable to a 'well-balanced and co-ordinated uniformity', in keeping with EU legal conformity. $^{2}$

As article no. 1 of the GDPR states, when defining the GDPR's subject-matter and objectives, firstly this Regulation lays down rules relating to the protection of natural persons with regard to the processing of personal data and rules relating to the free movement of personal data. Secondly, this Regulation protects fundamental rights and freedoms of natural persons and in particular their right to the protection of personal data. And thirdly, the free movement of personal data within the Union shall be neither restricted nor prohibited for reasons connected with the protection of natural persons with regard to the processing of personal data.

Based on these above-mentioned stipulations, the GDPR codifies in detail exemptions from the GDPR's scope, material and territorial scope. Certain exemptions and specific details are explicitly regulated by the GDPR concerning the research work that is related for example to the peer review process typically used in the world of science. This is analysed gradually below when analysing specific aspects of research.

In the context of this paper, the following main fields can be differentiated:

a) personal data of scholars within the scientific processes, like the peer review of articles, and grants, and also in processes where non-EU countries are involved;

b) personal data of scholars within organisations, like universities, etc.;

c) personal data of external persons gathered and processed in the framework of (social science) research.

\subsection{Research Aspects}

For the purposes of this paper, it is important to define research. When we talk about the legal definition of 'research', to be used in the whole European Union, we cannot find it, because no such uniform legal definition exists. However, there is generally accepted definition of 'research' adopted by the Organisation for Economic Co-operation and Development (OECD) in the so called Frascati Manual. As OECD itself claims on its own websites, the Frascati Manual was originally written by and for the experts in OECD member countries who collect and issue national data on research and development (R\&D). Over the years, it has become the standard of conduct for R\&D surveys and data collection not only in the OECD and in the European Union, but also in several non-OECD member countries and international organisations, for example, through the science and technology surveys of the UNESCO Institute for Statistics (UIS).

According to the Frascati Manual, version 2015, 'Research and experimental development (R\&D) comprise creative and systematic work undertaken in order to increase 
the stock of knowledge - including knowledge of humankind, culture and society - and to devise new applications of available knowledge'. ${ }^{3}$

The Frascati Manual identifies a set of common features of R\&D activities, even if these are carried out by different performers (not only research centres, universities, etc.). $R \& D$ activities may be aimed at achieving either specific or general objectives. $R \& D$ is always aimed at new findings, based on original concepts (and their interpretations) or hypotheses. It is largely uncertain about its final outcome (or at least about the quantity of time and resources needed to achieve it), it is planned for and budgeted (even when carried out by individuals), and it is aimed at producing results that could be either freely transferred or traded in a marketplace. For an activity to be an R\&D activity, it must satisfy five core criteria - these are the features described above.

For the purposes of this paper, it is also important to point out the distinctions of R\&D made by the Frascati Manual. The term R\&D covers three types of activity:

a) basic research,

b) applied research and

c) experimental development.

Basic research is, according to the Frascati Manual, experimental or theoretical work undertaken primarily to acquire new knowledge of the underlying foundations of phenomena and observable facts, without any particular application or use in view. On the other hand, according to the Frascati Manual, applied research is original investigation undertaken in order to acquire new knowledge. It is, however, directed primarily towards a specific, practical aim or objective. And experimental development is, according to the Frascati Manual, systematic work, drawing on knowledge gained from research and practical experience and producing additional knowledge, which is directed at producing new products or processes or at improving existing products or processes. ${ }^{4}$

The peer review process is not mentioned, only the scientific review is explicitly defined by the Frascati Manual. 'Scientific review' is included by the Frascati Manual as a part of R\&D in services. The Frascati Manual identifies, in addition to the above-mentioned five core criteria, the following indicators that help us to identify the presence of R\&D in service activities:

1. links with public research laboratories,

2. the involvement of staff with doctoral degrees or doctoral students and

3. the publication of research findings in scientific journals, together with the organisation of scientific conferences or involvement in scientific reviews. In the analysed document is not clear what exactly 'scientific reviews' means, i.e. if it means the peer review process of scholarly journals, peer review used by funding agencies or research assessment.

In the context of the Czech R\&D arena, there are Czech legal definitions of the three main research types - basic research, applied research and innovations in Act No. 130/2002 Coll. on the Support of Research and Development from Public Funds and on the Amendment to Some Related Acts (the Act on the Support of Research and Development). The definitions are fully in line with the OECD approach described above. It is explicitly stated in the Act that, in case of basic research, the results are published according to the customary practice in the scientific field. 


\section{GDPR AND OPEN ACCESS}

There is no legal definition of open access in EU law or Czech law. However, in the context of the European Union research area, the European Commission supports, through research and granting schemes (e.g. by FP7 or Horizon 2020) publication of research results in the open access mode. This is followed by Czech public managing research funding authorities such as The Ministry of Education, Youth and Sports (MEYS) or the Technology Agency of the Czech Republic (TA ČR).

The European Commission defines open access on its website as 'the practice of providing online access to scientific information that is free of charge to the end-user and reusable. 'Scientific' refers to all academic disciplines. In the context of research and innovation, 'scientific information' can mean:

- peer-reviewed scientific research articles (published in scholarly journals), or

- research data (data underlying publications, curated data and/or raw data). ${ }^{5}$

What if the personal data, protected by the GDPR, are part of the scientific results? How should this data be considered? In that case, it is obvious that the GDPR legislation 'brings' nothing new, it is clear that personal data protection should be respected as it was done according to previous legislation (and as it was the case in all EU member states' national legislations). Consequently, unauthorised publication of scientific results containing personal data is contra legem (both according to the GDPR and previous legislation).

\section{GDPR AND OPEN PUBLIC DATA IN THE PSI DIRECTIVE FRAMEWORK}

Even though we could see in the previous chapter that the European Commission includes research data in its definition of open access, still a distinction is made between open access and open data. The main difference is legislative and from this perspective the distinction between open access and open data is that the latter falls under the PSI directive. What the Czech legislator considers open data (see below), is in EU legislation called public sector information. In the case of the national legislation of the EU member states there is a common legal background, thanks to EU Directive 2003/98/EC of the European Parliament and of the Council of 17 November 2003 on the re-use of public sector information (PSI Directive). This legislation supports the re-use of information held by public institutions publishing the respective information in the form of open data accessible to anyone for any purposes (e.g. meteorological data for transport purposes). An examination of how commercial exploitation could help to maximise the value of this public sector information (PSI) to governments, citizens and business alike has been published by the European Commission in the following documents Pira International Ltd., University of East Anglia and KnowledgeView Ltd. (2014), Commercial exploitation of Europe's public sector information, executive summary and later in other European Commission's studies, such as W. Carrara (2017), Open Data Maturity in Europe, Open Data for a European Data Economy or M. Barbero (2018), support the review of Directive 2003/98/EC on the re-use of public sector information. It must be underlined, as it was written above, that the PSI Directive itself instead of the term 'open data' uses the term 'public sector information'.

However, in the case of the research data of the public research institutions there used to be an exemption not to apply the PSI Directive on the documents of the scientific and academic institutions. Till the PSI Directive amendment of Directive 2013/37/EU of the

5 European Commission (2018). 
European Parliament and of the Council of 26 June 2013 amending Directive 2003/98/EC on the re-use of public sector information (Text with EEA relevance) in 2013, it used to be stipulated by the EU legislator in Article 1, Paragraph e) of the PSI Directive that documents of educational and research institutions, including organizations established for the transfer of research results, schools and universities, except for university libraries, are exempt from the application of this directive. The situation before PSI amendment, when research institutions were not included in the PSI directive, had been widely criticised. ${ }^{6}$ This PSI Directive amendment was in the end approved. This was done despite the fact that according to the European Commission communication published in $2009^{7}$ the EU member states (except Latvia and Lithuania) and stakeholders representing the excluded sectors considered that the scope of the PSI Directive exemption should not be widened. The main argument of the member states and stakeholders was the administrative burden and associated costs that would not be outweighed by the potential benefits. They pointed out that a large part of the material held by these institutions is also covered by third party intellectual property rights, and would not, therefore, in any case fall within the scope of the PSI Directive.

Regarding personal data protection, the PSI Directive itself states in its article no. 1 letter 2.cc that this Directive shall not apply to documents access to which is excluded or restricted by virtue of the access regimes on the grounds of protection of personal data, and parts of documents accessible by virtue of those regimes which contain personal data the re-use of which has been defined by law as being incompatible with the law concerning the protection of individuals with regard to the processing of personal data.

In case of the Czech jurisdiction, the PSI Directive was implemented via an amendment of the Act No. 106/1999, Coll. on Free Access to Information. In its $\S 3$ (11) it defines 'open data' for the purposes of this Act as an information published in a manner enabling remote access in an open and machine-readable format. Moreover, the manner and purpose of the subsequent use of such information should not be restricted and the information should be recorded in the Open Data National Catalogue. ${ }^{8}$

As far as the scientific world is concerned, in case of the Czech legislation it is not obligatory for research and academic institutions to provide their scientific data openly. According to the $\S 4 \mathrm{~b}(2)$, obligatory entities publish information contained in registries, archives, records or lists maintained or administered by such entities; such information is accessible to every person by law and can be used as open data for business or other profitable activities, for study or scientific purposes or for public inspections of legally bound persons. Legally bound persons register such information in a National Open Data

${ }^{6}$ See Jančič (2012).

7 See the European Commission communication in the following English version published by European Commission (2009a) Communication from the Commission to the European Parliament, the Council, the European Economic and Social Committee and the Committee of the Regions Re-use of Public Sector Information - Review of Directive 2003/98/EC. See in more detail in the following version of the Commission communication that has the same Celex identification but it is published only in English version and interestingly this document has 36 pages (the former mentioned English version has 8 pages) European Commission (2009b) Commission Staff Working Document Accompanying document to the Communication from the Commission to the European Parliament, the Council, the European Economic and Social Committee and the Committee of the Regions Re-use of Public Sector Information - Review of Directive 2003/98/EC.

8 Concerning the database rights and licencing, see Bottis (2015) and Myška and Harašta (2016). 
Catalogue. The list of obligatory information (open data) is set forth by an implementing legal regulation, currently by Government Resolution No. 425/2016 Coll., dated 14 December 2016. The Government Resolution currently defines 11 data sets. For the publication of these obligatory data sets in open data format only certain Czech ministries (e.g. Ministry of Transport, Ministry of Interior) are currently responsible. According to the Czech Government Mid-Term Self-Assessment Open Government Partnership Action Plan Report of the Czech Republic for 2016-2018, this report fully completes the commitments defined in the previous Open Government Partnership Action Plans. It is paradoxical that even though there was an amendment of the PSI Directive in 2013 extending the realm of open data (resp. public sector information for research institutions), in the context of the Czech scientific world, it does not currently have any legal impact. In case of the Czech scientific and academic arena, we do not have to worry. Especially compared with other conflicting areas, such as trade secrets protection, where in the context of the EU legislation (PSI Directive) a legislative policy recommendation on trade secret is given. ${ }^{9}$ There is also no conflict between PSI Directive implementation and the GDPR (e.g. obligation to publish any scientific data containing personal data).

On the other hand, scientific and academic institutions are pushed and motivated by the research funding agencies to provide their scientific data (e.g. for reuse of the sociological interviews, medical and clinical trials) openly however with respect to the relevant legislation (including e.g. trade secrets, personal data protection). In case a public research or academic institution provides open scientific data containing personal data and breaches that way the GDPR (e.g. unauthorised publication of personal data), it is highly probable that the breaching institution would be legally responsible for non-respecting the GDPR. The reasons for this conclusion are:

1. Currently there is no Czech entity lawfully (de lege) obliged to provide scientific data in open data format.

2. Personal data protection currently has higher legal protection (GDPR) than open data policy (PSI Directive). That is a case of 'EU regulation vs. EU directive'.

3. In case of breach of the GDPR rules by public authority, objective responsibility based on the judgment of the Supreme Court of the Czech Republic of 20 December 2006 (no. 25 Cdo. 2840/2004) could also be applied. It follows from that judgment that the maladministration also involves the disclosure of incorrect information (in our case, incorrect information equals scientific data containing unauthorised personal data). ${ }^{10}$

\section{GDPR AND FREE ACCESS TO INFORMATION LEGISLATION}

Czech public universities and public research entities are, according to the Czech legislation (Act No. 106/1999 Coll. on Free Access to Information), legally bound under a duty to provide information related to their authority in two ways. They are de lege obliged to publish the legally obligatory information, such as the reason and method of the establishment of the legally bound person, including the conditions and principles under which it performs its activities, a description of its organizational structure (this might include, for example, working contacts of the employed researchers), an annual report on its activities in the field of providing information. Alternatively, it should provide

9 Dinca (2012).

10 Complex analysis of responsibility of the Czech open data provider, see Míšek (2016). 
information upon request to any applicant (regardless of whether it is a natural person or a legal entity).

Both situations (legally obligatory information and information provision upon request) have been regulated in a way to respect personal data protection and are fully in line with the GDPR as well. This means, for example, that if the information applicant applied for a scientific result containing personal data on the legal basis of this law, the application should be rejected resp. the requested information should be provided in a manner that respects the GDPR (if it is feasible either with anonymous data and/or with authorized personal data). ${ }^{11}$

\section{GDPR AND PEER REVIEW}

What can be the main impacts of the GDPR on the peer review process in scholarly journals? Will there be any different impact on peer review used by funding agencies or research performance assessment? Will there be any significant difference compared with the current state? What sort of the necessary steps should be taken by the stakeholders?

The peer review process in scholarly journals has been used for the last three centuries, mainly in basic research. As it is used by the international scientific community no formal, international and legally binding rules exist but it is regulated by traditional approaches (anonymity of the reviewers, more than one review of the submitted text, single blind and double blind processes, etc.). These opaque informal rules do not provide clear legal entitlement to handling the personal data of the authors and reviewers within the peer review process and afterwards (in publishing the manuscript).

Single blind peer review refers to a review system where reviewers remain anonymous to the authors. According to N. H. Koroso, ${ }^{12}$ in the case of the double blind review, both the authors and the reviewers are anonymous to each other. From the GDPR point of view, in case of submission of the text for review in double blind review it is not necessary to receive the authors' consent to handling their personal data by the editor, because the personal data are not shared with third parties (reviewers) and in case of successful publication, authors are aware that their authorship will be revealed. However, currently the peer review process absorbs a lot of new forms and trends that differ from the traditional peer review approaches. This is often generally interrelated with the open access movement in science. The main new approaches are the open peer review and the second one is the post peer review.

Open peer review requires that the manuscripts, the reviewers' names and comments and the authors' response should all be made available for public scrutiny. Here, according to Koroso, authors and the public see who reviewed their work. In this case, to be in line with the GDPR, it would be advisable that the editor receive the consent to the handling of personal data not only from the author but also from the manuscript reviewer whose review will be published as well.

Post peer-review happens after unreviewed articles are published or put online. The objective is, as Koroso points outs, to replace or improve the pre-publication peer review with post-publication comments and criticisms. In this type of process and in the context of

11 Conflicting issues of personal data protection with free access to information legislation are in more detail analysed by Novák (2014), Petr Kolman and Jiri Kolman (2016).

12 Koroso (2016). 
GDPR, if the reviewers are made public (they are not anonymous), consents are also necessary from both groups, manuscript authors and reviewers.

Within the main principles of GDPR, in both above-mentioned cases (open peer review, post peer-review) only the necessary personal data of the authors and reviewers (e.g. working contacts, employers' affiliation) should be requested for publishing by the editor.

Peer review used by funding agencies for scientific merit evaluation of grant applications (not only supporting basic research but also in applied research and experimental development projects and programmes) has been used for several decades and is more formally bound by the rules of the involved agency (funder of the positively evaluated research applications). Usually, legal grant applicants' consent is already requested (i.e., before the legal enforcement of the GDPR). This happens in cases where personal data is relevant (e.g. individual scholarships applications). The application reviewers (usually external, not employed in the funding agency) are anonymous and under confidentiality rules. Some of the funding agencies (e.g. the European Commission) regularly (in case of the European Commission annually) publish the lists of the reviewers involved in the evaluation process. However, it is not revealed which concrete project applications were reviewed by whom. Apart from the already mentioned consent of the grant submitting persons in certain cases, the consent of the reviewers in case of publication of their names is needed as well.

Peer review process is used in research assessment of institutions involved in all types of research activities (basic research, applied research and experimental development) and it is close to the process used in the previous case, in peer review used by funding agencies for scientific merit evaluation of the grant applications. Usually, this process consists of two parts - the review of the provided assessment documents and on-site visit or interviews of the representatives of the assessed institution (or research team, faculty, laboratory...). Usually the reviewers' names are not published or are published names within the work of the external assessment bodies, such as scientific advisory boards, where the reviewers are members. In case of the handling of the personal data of the reviewers and especially in case of the publication of their names and other related personal data, their consent should be received.

\section{THE GDPR AND INTERNATIONAL COLLABORATIONS (CONSORTIUM PROJECTS AND RESEARCH INFRASTRUCTURES)}

In the scientific world, international collaboration is typical, mainly via multilateral projects and consortiums and long-term research infrastructures [mainly in the EU, see ERIC European research infrastructure consortium legal framework regulated by Council Regulation (EC) No 723/2009 of 25 June 2009 on the Community legal framework for a European Research Infrastructure Consortium (ERIC)]. All the EU member countries have legislation dealing with personal data protection. This means that, notwithstanding the free movement of scientific data and results, international scientific collaborations should also respect personal data protection. In case of ERIC legal entities that operate according to EU legislation and secondarily (when the EU appropriate legislation is missing) according to the national legislation, where the ERIC legal seat is located, it is the responsibility of the ERIC members. It should be pointed it out here that, officially, the national governments themselves are ERIC members and participating research entities are delegated (entitled) by ERIC member governments to ERIC scientific activities. It is important to remember that 
when an ERIC legal entity is prepared, the legal check is provided by the European Commission and data issues (including personal data protection) are also part of the legal check of the ERIC founding documents.

In case of scientific collaboration with third (non-EU) countries, there are different approaches to personal data protection, especially between the US and Europe. This might have an impact on the sensitivity of personal data issues within these types of scientific collaborations. For example, the general approach of the legislation regulating the protection of personal data is different in the EU and in the US. Under the US law, protection of privacy in fact constitutes a protection of an individual against the state, while in the EU, protection is based on the intention of an individual to control his/her public image, i.e. not only in relation to the state authority but also in relation to the general public. ${ }^{13}$

Generally speaking, from the federal level, in the US, public legal protection is provided mainly via civil law. In the case of Europe, the protection is provided by the public authorities (e.g. in case of the Czech Republic it is the Office for Personal Data Protection) and the civil law can be used in case of e.g. an action for compensation of the damages. This difference in perception of privacy is probably based on different historical experience, because Europe has a rich experience with totalitarian regimes abusing the personal data of their citizens.

\section{GDPR AND TECHNICAL MEASURES AND SOLUTIONS - FROM LEGAL POINT OF VIEW}

According to the current political debate in the Czech parliament where the implementation of the GDPR Regulation is being prepared and from the above mentioned argument that in the context of the Czech legal system regulating the personal data protection, there will not be any big changes (apart from lowering certain aspects of the level of the personal data protection, e.g. the maximum amount of the fines) in new legal measures (not too many new legal rules). However, the control of the implementation of the data protection by the data controller or processor is more tighten and more strict by GDPR. E.g. certain infringements of the GDPR provisions shall be subject to administrative fines up to 20000000 EUR, or in the case of an undertaking, up to $4 \%$ of the total worldwide annual turnover of the preceding financial year depending on which value is higher. In the context of the Czech Republic, it should be compared with the previous relevant personal data protection Czech legislation (Act No. 101/2000 Coll. On the Protection of Personal Data and on Amendments to Certain Acts) stipulating a maximum fine of up to $10000000 \mathrm{CZK}$ that is equivalent to approximately 393159 EUR. ${ }^{14}$

GDPR regulation also requires appropriate technical and organisational measures to be taken to ensure that the requirements of the regulation are met. In order to be able to demonstrate compliance with this regulation, the controller should adopt internal policies and implement measures which meet in particular the principles of data protection by design and data protection by default. Usually, especially in case of research organisations not having big IT departments and in case of collaborative research consortium projects, the technical solutions protecting personal data are realised in collaboration with third parties

13 Whitman (2004).

14 The official exchange rate of the Czech National Bank for 24 April 2018 for 1 EUR was 25,435 CZK. 
(e.g. IT companies, consortium partner organisations). In such cases, it is necessary to have a concluded agreement between the parties (research organisation and the processor) on the protection of the processed personal data.

It is, widely agreed upon that in a research environment the entire C.I.A. set of requirements (viz. Confidentiality, Integrity, Availability) should be adhered to all the time, since the breach of data integrity can severely lead a research project astray, and losing access to research data can hinder or completely derail the research. From the IT (technical) point of view the biggest threat facing personal data protection, among other various data incidents, is data loss. Data loss can happen in various forms, ${ }^{15}$ it might be either accidental, such is an email sent to the wrong address (person) or loss of a USB drive, or it can be on purpose (e.g. by an unsatisfied employee of the data controller or processor).

The following main forms of data leaks can be identified:

a) Email (Attachments, Webmail, Email client);

b) Cloud (Box, Dropbox, Google Disk, OneDrive);

c) Hardware (USB drives, Memory Cards);

d) Internet (Web, p2p, FTP, torrent);

e) Media (CD, DVD, Blu-ray, Print);

f) Mobile (Mobile phone, Tablet, Laptop);

g) Social Media (Facebook, Twitter, Google+, IM);

h) Clipboard (Keylogger, Screenshot, $\mathrm{Ctrl}+\mathrm{c} / \mathrm{Ctrl}+\mathrm{v}$.

There is a technical solution providing protection against the data loss identified above that consists of three main steps:

1. Detection of the data controllers and processors' personal data security threats.

2. Data security rules tailor-made for the data controllers and processors considering specific IT conditions and the specifics of the personal data content.

3. Providing prevention of the sensitive data from leaving responsible entity (data controller and processor).

Current technology can provide alerts when somebody is using personal or confidential data or information irresponsibly personal or confidential data or information. Depending on which technological mode it is operating in, it can automatically either block the risky activity, inform an administrator (resp. data controller and processor about any data incident), or remind responsible person handling irregularly (oddly) with the personal data of the security guidelines. When a sensitive document with personal data needs to be removed from the institution (e.g. in case of research activity done out of the laboratory, e.g. on a USB drive or laptop), it can be encrypted via specific software that is interrelated with the whole IT system used by the data controller and the processor institution. Nobody who is not authorised can access the personal data unless it is authorised by the controller or processor. This also provides a measure of security even if e.g. a USB drive or laptop gets lost or stolen.

This technical approach toward the protection of the personal data is fully in line with the GDPR rules and GDPR six principles stipulated in GDPR article no. 5 and its main goal, that is, the protection of natural persons with regard to the processing of personal data. In the context of the specific academic and scientific world this technological approach is suitable as well and no specific legal threats appear. 


\section{CONCLUSION}

As it is obvious from above text, in most described cases, such as the peer review process and other specific academic activities, no significant impact of the new GDPR legislation can be foreseen in case of the Czech academia.

However, another important question in the context of this paper is if research activities themselves (also within the notion of the freedom of scientific research and academic freedoms) will be affected by the GDPR. For example, will it be possible to disclose personal data of the reviewers to researchers focusing on peer review process research? From the GDPR legislation point of view, the research itself should not be affected because firstly, the GDPR is regulating the personal data rights of living persons and secondly, there is a general GDPR exemption for personal data handling for research purposes. This 'scientific purposes exemption' is stipulated mainly in GDPR article no. 5 that regulates principles relating to the processing of personal data, which states in (b) that personal data collected for specified, explicit and legitimate purposes and not further processed in a manner that is incompatible with those purposes; further processing for archiving purposes in the public interest, scientific or historical research purposes or statistical purposes shall, in accordance with GDPR Article 89(1), not be considered to be incompatible with the initial purposes ('purpose limitation').

GDPR Article 89(1) regulates in detail safeguards and derogations relating to processing for archiving purposes in the public interest, scientific or historical research purposes or statistical purposes. The GDPR Article 89 can be considered as a sort of alleviation for the research activities and, on the other hand, it does not jeopardise the main purpose of the GDPR. It remains to be seen if that was a wise decision of the EU legislator to provide such a 'scientific purposes exemption.' The main risk might be to use the exemption as a pretext for the misuse of personal data for e.g. commercial sake.

Concerning the existing technological measures, preventing data loss containing personal or other sensitive data in the context of the specific academic and scientific world, the existing legislation is legally appropriate. It is in accordance with the GDPR and with the intention of the EU legislator that is envisaged among others in the first paragraph of the GDPR preamble:

The protection of natural persons in relation to the processing of personal data is a fundamental right. Article 8(1) of the Charter of Fundamental Rights of the European Union (the 'Charter') and Article 16(1) of the Treaty on the Functioning of the European Union (TFEU) provide that everyone has the right to the protection of personal data concerning him or her.

\section{LITERATURE}

Barbero, Martina et al., Study to support the review of Directive 2003/98/EC on the re-use of public sector information (Publications office of the European Union 2008) $<\mathrm{https}$ :/publications.europa. eu/en/publication-detail/-/publication/45328d2e-4834-11e8-be1d-01aa75ed71a1/language-en> accessed 11 November 2018.

Bottis, Maria, 'How Open Data Become Proprietary in the Court of Justice of the European Union' in Sokratis, Katsikas and Sideridis, Alexander (eds), E-Democracy - Citizen Rights in the World of the New Computing Paradigms (Springer International Publishing 2015) 169-74.

Carrara, Wendy, Open Data Maturity in Europe, Open Data for a European Data Economy (European Data Portal 2009). <https://www.europeandataportal.eu/sites/default/files/edp_landscaping_ insight_report_n3_2017.pdf> accessed 11 November 2018. 
Government Resolution No. 425/2016 Coll. On the list of information published as open data. The Czech Republic. Prague: Sbírka zákonů ČR (in Czech).

Jančič, Maja Bogataj et al., 'Policy Recommendation as to the Issue of the Proposed Inclusion of Cultural and Research Institutions in the Scope of PSI Directive - Working Group 5.' (2012) 6 Masaryk University Journal of Law and Technology 353-72.

Judgment A. s.r.o. vs. the Ministry of Industry and Trade of the Czech Republic (2006) the Supreme Court of the Czech Republic, 20. December 2006 (no. 25 Cdo 2840/2004, in Czech).

Kolman, Petr and Kolman, Jiri. (2016): Free Access to the Documents and Information of the EU Institutions from the Point of View of Czech Legislation. Hungarian Journal of Legal Studies, 57 (4), pp. 477-488, p. 478.

Koroso, Nesru, 'Open and Post Peer Review: New Trends in Open Access Publications' (2016) UA Magazine Connecting Science and Society $<$ https://www.ua-magazine.com/open-post-peerreview-new-trends-open-access-publications/> accessed 11 November 2018.

Míšek, Jakub 'Odpovědnost poskytovatele otevřených dat za škodu vyplývající $\mathrm{z}$ chyb $\mathrm{v}$ poskytovaných datových sadách' (Open data provider's liability for damage resulting from errors in the provided datasets) (2016) 49 Správní právo 427-37.

Myška, Matěj and Harašta, Jakub, 'Less Is More? Protecting Databases in the EU after Ryanair' (2016) 10 Masaryk University Journal of Law and Technology 170-98.

Novák, Daniel, 'Zákon o ochraně osobních údajů a předpisy související: komentáŕ' (Personal Data Protection Act and Regulations: Commentary,) (Wolters Kluwer Práha 2014).

Varga, Csaba, 'Legal Theorising An Unrecognised Need for Practicing the European Law' (2009) 50 Acta Juridica Hungarica 415-58.

Whitman, James, 'The Two Western Cultures of Privacy: Dignity versus Liberty' (2004) 113 Yale Law Journal 1151-221.

\section{LINKS}

1. Regulation (EU) 2016/679 of the European Parliament and of the Council of 27 April 2016 on the protection of natural persons with regard to the processing of personal data and on the free movement of such data, and repealing Directive 95/46/EC (General Data Protection Regulation GDPR) <http://eur-lex.europa.eu/legal-content/EN/TXT/PDF/?uri=CELEX:32016R0679\&rid=1> accessed 23 December 2018.

2. Act No. 106/1999 Coll. on Free Access to Information. The Czech Republic (in Czech) $<$ https:// www.zakonyprolidi.cz/cs/1999-106> accessed 23 December 2018.

3. Frascati Manual 2015, 'Guidelines for Collecting and Reporting Data on Research and Experimental Development, The Measurement of Scientific, Technological and Innovation Activities. Organisation for Economic Co-Operation and Development (OECD) (2017) <http:// www.oecd-ilibrary.org/docserver/download/9215001e.pdf?expires $=1513286734 \& \mathrm{id}=\mathrm{id} \&$ accna me $=$ guest $\&$ checksum $=44$ C0856E1A164785BF3BC694CE3FD0C4 $>$ accessed 23 December 2018.

4. Act No. 130/2002 Coll. on the Support of Research and Development from Public Funds and on the Amendment to Some Related Acts (the Act on the Support of Research and Development). The Czech Republic (in Czech) <https://www.zakonyprolidi.cz/cs/2002-130> accessed 23 December 2018.

5. European Commission (2018), 'Participant Portal H2020 Online Manual. Open Access' < https:// ec.europa.eu/research/participants/docs/h2020-funding-guide/cross-cutting-issues/open-accessdata-management/open-access_en.htm> accessed 23 December 2018.

6. Pira International Ltd., University of East Anglia and Knowledge View Ltd. (2014), 'Commercial exploitation of Europe's public sector information - executive summary. Luxembourg: Office for Official Publications of the European Communities' <ftp://ftp.cordis.europa.eu/pub/econtent/ docs/2000_1558_en.pdf $>$ accessed 23 December 2018.

7. Directive $2003 / \overline{98} / \mathrm{EC}$ of the European Parliament and of the Council of 17 November 2003 on the re-use of public sector information $<\mathrm{http}$ //eur-lex.europa.eu/legal-content/EN/TXT/PDF/?uri $=$ CELEX:32003L0098\&qid=1515759020342\&from=EN $>$ accessed 23 December 2018. 
8. Directive 2013/37/EU of the European Parliament and of the Council of 26 June 2013 amending Directive 2003/98/EC on the re-use of public sector information <http://eur-lex.europa.eu/ legal-content/EN/TXT/PDF/?uri=CELEX:32013L0037\&qid $=1515708332905 \&$ from $=$ CS $>$ accessed 23 December 2018.

9. European Commission 'Communication from the Commission to the European Parliament, the Council, the European Economic and Social Committee and the Committee of the Regions Re-use of Public Sector Information - Review of Directive 2003/98/EC' (2009a) $<$ http://eur-lex.europa.eu/legal-content/EN/TXT/PDF/?uri=CELEX:52009DC0212\&from=EN> accessed 23 December 2018.

10. European Commission 'Commission Staff Working Document Accompanying document to the Communication from the Commission to the European Parliament, the Council, the European Economic and Social Committee and the Committee of the Regions Re-use of Public Sector Information - Review of Directive 2003/98/EC (2009b) <http://eur-lex.europa.eu/ legal-content/EN/TXT/PDF/?uri=CELEX:52009SC0597\&qid=1515705899514\&from=CS> accessed 23 December 2018.

11. Czech Republic 2017 Mid-Term Self-Assessment Open Government Partnership Action Plan Report of the Czech Republic for 2016-2018. <http://www.korupce.cz/assets/partnerstvi-prootevrene-vladnuti/Mid-Term-Self-Assessment-Open-Government-Partnership-Action-PlanReport-of-the-Czech-Republic-2016-2018.pdf> accessed 23 December 2018.

12. Council Regulation (EC) No 723/2009 of 25 June 2009 on the Community legal framework for a European Research Infrastructure Consortium (ERIC) <http://eur-lex.europa.eu/legalcontent/EN/TXT/PDF/?uri=CELEX:32009R0723\&qid=1515969205279\&from=CS $>$ accessed 23 December 2018.

13. Act No. 101/2000 Coll. On the Protection of Personal Data and on Amendments to Certain Acts (c. 32/2000). The Czech Republic (in Czech) <https://www.zakonyprolidi.cz/cs/2000-101> accessed 23 December 2018.

14. Safetica Technologies 'There are lots of ways to lose control of your data. (2018) $<$ https://www. safetica.com/how-safetica-helps/data-protection> accessed 23 December 2018. 